\title{
0 bem-estar dos agregados familiares rurais em Timor- Leste: uma abordagem baseada na programação linear etnográfica
}

\author{
The well being of rural households in Timor-Leste: An approach using \\ ethnographic linear programming
}

\author{
Carlos de Deus ${ }^{1}$ (1), Maria Leonor da Silva Carvalho ${ }^{2}$ (1), Vanda Narciso ${ }^{3}$ (1), \\ Pery Francisco Assis Shikida ${ }^{4}$ (D), Maria Raquel Lucas ${ }^{5}$ (), Pedro Damião Henriques ${ }^{5}$ (b) \\ ${ }^{1}$ Universidade Nacional Timor Lorosa'e (UNTL), Díli, Timor-Leste. E-mail: lito.uevora@gmail.com \\ ${ }^{2}$ Investigador independente, Lisboa, Portugal. E-mail: nono.verdete@gmail.com \\ ${ }^{3}$ Investigador independente, Évora Portugal. Email: vandanarciso@gmail.com \\ ${ }^{4}$ Universidade Estadual do Oeste do Paraná (UNIOESTE), Toledo, Brasil. E-mail: peryshikida@hotmail.com \\ ${ }^{5}$ Universidade de Évora, Centro de Estudos e Formação Avançada em Gestão e Economia (CEFAGE), Évora, Portugal. E-mails: \\ mrlucas@uevora.pt; pdamiao@uevora.pt
}

\begin{abstract}
Como citar: Deus, C., Carvalho, M. L. S., Narciso, V., Shikida, P. F. A., Lucas, M. R., \& Henriques, P. D. (2021). O bem-estar dos agregados familiares rurais em Timor-Leste: uma abordagem baseada na programação linear etnográfica. Revista de Economia e Sociologia Rural, 59(1), e238878. https://doi.org/10.1590/1806-9479.2021.238878
\end{abstract}

Resumo: A agricultura em Timor-Leste é de natureza familiar e um modo de vida para as populações rurais, que são a maior parte da população. O objetivo deste trabalho é medir o bem-estar dos agregados familiares tendo como principal indicador o rendimento disponível, com base em atividades produtivas, reprodutivas e comunitárias, as quais são centrais à organização e ao funcionamento das comunidades rurais timorenses. A metodologia utilizada para representar o funcionamento dos agregados familiares é a programação linear etnográfica (PLE), que permite testar políticas, tecnologias, alterações reprodutivas e mudanças das normas sociais comunitárias, explorar os respetivos resultados e prever as consequências para o futuro dos agregados familiares e das comunidades rurais. Os resultados mostram que os agregados familiares com explorações agrícolas de pequena e, em alguns casos, também as de média dimensão, nas condições atuais, não geram rendimento suficiente para níveis de consumo e bem-estar acima da linha da pobreza. Alternativas de apoio ao rendimento, como o apoio direto ao rendimento, são possíveis, mas dependem dos recursos disponíveis para a sua implementação, enquanto, em médio e longo prazo, o aumento da área das explorações afigura-se uma opção mais válida para quebrar o ciclo vicioso da pobreza.

Palavras-chave: sistema de agricultura, bem-estar dos produtores, linha da pobreza, programação linear etnográfica, Timor-Leste.

Abstract: Agriculture in Timor-Leste is family-based and a way of life for the rural population who are most of the population. The objective of this work was to measure the well-being using as the main indicator the disposable income, considering not only productive activities but also reproductive and community activities, which are central to the organization and functioning of East Timorese rural communities. The methodology used to represent the functioning of households was the ethnographic linear programming (ELP), which models allowed to test policies, technologies, reproductive changes and changes in community social norms, as well as explore their results and predict the consequences for the future of households and rural communities. The results showed that households with small farms, and in some cases also medium-sized ones, under current conditions do not generate enough income for levels of consumption and well-being above the poverty line. Alternatives of income support, such as direct income support, are possible but depend on the resources available for their implementation, while in the medium and long term the increase in holdings area is a more valid option to break the vicious cycle of poverty.

Keywords: agriculture system, producer welfare, poverty line, ethnographic linear programming, TimorLeste. 


\section{INTRODUÇÃO}

A agricultura familiar, dominante em muitas regiões do planeta, tem como características principais ter terra e capital limitados; mão de obra predominantemente familiar; o chefe de família a participar diretamente no processo produtivo, e a produção agrícola como principal fonte de receitas, podendo ser complementada com atividades fora da unidade familiar (Food and Agriculture Organization, 2012). Na agricultura familiar, a família e a exploração agrícola estão intimamente ligadas, coevoluindo e combinando as funções econômicas, sociais, ambientais e culturais. As relações familiares têm implicações importantes sobre decisões de produção, tais como a escolha das culturas; a organização do trabalho familiar e sua alocação em diferentes tarefas (agrícolas, familiares, comunitárias e festivas), e a gestão de terras agrícolas e de outros bens, e das questões de herança (Garner et al., 2014).

Timor-Leste é uma pequena ilha montanhosa com uma área de cerca de $19.000 \mathrm{~km}^{2}$ composta por 12 municípios e uma região autônoma. Cada município tem as suas próprias características geográficas, edáficas e climáticas, que determinam as culturas vegetais e animais, as tecnologias de produção e o estabelecimento e desenvolvimento de outras práticas ligadas à agricultura.

Na Ásia Pacífico à qual se integra Timor-Leste, a agricultura, predominantemente familiar, apresenta características marcantes para o desenvolvimento agrícola e o bem-estar das populações rurais: a subsistência e a satisfação das condições de vida; a centralidade da família; a intensificação do trabalho; a diversificação, a pluriatividade e a redução do risco; a autonomia e a integração deliberada no mercado; a endogeneidade e a localidade; a autossuficiência e a segurança alimentar; ser ambientalmente amigável, e a herança cultural (Ye \& Pan, 2016).

Em Timor-Leste, a agricultura é de natureza familiar, de baixa produtividade, de subsistência e de pequena escala. É sustentada em culturas, como o arroz, o milho e o café. Muitos agricultores também criam gado. Os proprietários de um grande número de cabeças de gado são, em geral, pessoas importantes na sociedade e estão quase sempre envolvidos nos eventos mais relevantes das comunidades. Os animais são ativos valiosos para ajudar os agricultores nos tempos difíceis, nomeadamente para fazer face a necessidades de emergência, como são as das escolas das crianças, a falta de alimentos básicos na estação chuvosa ou os funerais de família.

Os rendimentos por hectare e/ou por unidade de produção são, geralmente, mais baixos do que os encontrados em outros países asiáticos (Asian Development Bank, 2015), em quase todas as atividades agrícolas e pecuárias e também na pesca (World Bank, 2018). Esta baixa produtividade decorre, sobretudo, de um acesso muito limitado à tecnologia e a fatores de produção. Aumentar o bem-estar dos pequenos agricultores passa por caracterizar os sistemas agrícolas existentes e avaliar o seu contributo no desenvolvimento econômico e na redução da pobreza.

O problema de investigação base deste estudo centra-se no bem-estar dos agregados familiares de Timor-Leste, com especial atenção para os que apresentam níveis de consumo abaixo da linha de pobreza.

Face ao exposto, o objetivo deste trabalho é o de realizar uma análise dos sistemas de agricultura, focada no bem-estar dos agregados familiares, tendo como principal indicador o resultado líquido. Pretende-se analisar a diversidade, complexidade e globalidade dos sistemas de agricultura e dos agregados familiares, integrando as suas diversas dimensões (produção, consumo, atividades doméstica, comunitária e festiva).

Depois desta introdução, faz-se a descrição da metodologia e a implementação empírica dos modelos utilizados. Os resultados dos modelos e sua discussão são apresentados na quarta seção do artigo, terminando com as conclusões.

\section{METODOLOGIA}

$\mathrm{Na}$ análise da agricultura familiar e de subsistência, são utilizados os modelos baseados na teoria neoclássica da produção e do consumo, e os modelos baseados na programação matemática. Aqueles exigem uma bateria de dados dos agregados familiares, para a 
estimação econométrica dos parâmetros dos modelos, o que não existe em Timor-Leste, sendo essa então a razão para a sua não escolha.

Assim, o método escolhido para analisar os agregados familiares rurais de Timor-Leste foi a programação linear, mais concretamente a programação linear etnográfica (PLE). Os primeiros modelos de programação linear aplicados à agricultura e à economia agrícola, surgidos na década de 1950, eram modelos de natureza normativa que antecipavam o que deveria ser feito, sendo muito usados no planeamento agrícola para ajudar os agricultores na tomada de decisão sobre a organização e uso dos recursos, e aumento dos resultados econômicos (Heady, 1958).

A programação linear etnográfica (PLE), surgida na década de 1990, herdeira direta da programação linear, incorpora não só a dimensão produtiva dos agregados familiares, mas também a dimensão reprodutiva, pois uma parte significativa dos recursos é consumida nesta última dimensão, assim como na sociocultural. Junta-se a programação linear, um método quantitativo, à etnografia, um método de pesquisa qualitativa, utilizada para aprofundar a compreensão sociocultural dos agregados familiares (Bernard, 1995). O propósito da etnografia é compreender: 1) o que é feito; 2) quem faz o quê; 3) quando é feito; 4) como é feito; e 5) por que razão é feito (Wilsey et al., 2012). Gerando modelos de natureza heurística, de suporte à tomada de decisão, a PLE considera a dimensão humana no sistema, sendo uma ferramenta básica na análise dos sistemas de agricultura de subsistência nas suas dimensões produtiva, reprodutiva e social (Hildebrand et al., 2003). $\mathrm{Na}$ dimensão reprodutiva, estão incluídas tarefas, como a preparação da alimentação; cuidar dos filhos/crianças; lavar a roupa; cuidar da casa; recolher água, lenha e plantas selvagens para a alimentação e saúde, e cuidar dos animais e das hortas. Na dimensão social, inclui-se a participação nas atividades comunitárias e festivas. Para além da maximização do lucro das atividades produtivas, um agregado familiar tem outros objetivos, que incluem a satisfação das atividades reprodutivas e as do grupo a que pertence. Neste estudo, separaram-se as atividades comunitárias e festivas pelo fato de as festivas serem muito relevantes em Timor-Leste.

O objetivo do modelo de PLE desenvolvido foi o de estudar os agregados familiares em cada um dos quatro distritos considerados, de modo a analisar e identificar as variáveis que diferenciam os agregados familiares e os seus sistemas de agricultura, além de avaliar o rendimento, maximizando o bem-estar dos agregados familiares.

Neste modelo, existe um conjunto de atividades representando a produção, a reprodução do agregado familiar e a relação deste com a comunidade em que está inserida e na qual se inscrevem os deveres e as obrigações. A sua matriz básica representa um agregado familiar com três componentes: as atividades de produção disponíveis no agregado e fora do agregado familiar, as atividades reprodutivas comuns e todos os recursos disponíveis expressos através de restrições. Na modelação dos recursos, são elementos importantes: 1) a sazonalidade, devido à possibilidade de escassez de recursos em alguns períodos; 2) a desagregação da utilização de alguns recursos, como, por exemplo, a mão de obra, entre jovens e idosos, e por gênero, porque, em muitos contextos, as tarefas agrícolas e reprodutivas dependem do gênero (preparação da terra, sementeira, monda, colheita, cuidar dos filhos, recolha de lenha e água, cozinhar, entre outras) e/ou da idade. O detalhe das observações exigidas pelas características etnográficas dos agregados e as necessidades para a modelação resultaram em modelos de dimensões relativamente elevadas em restrições e variáveis.

A estrutura formal básica do modelo de PLE pode ser descrita ou explicitada na forma matricial seguinte:

Função Objetivo:

$\operatorname{Max} E(Z)=-C_{v} X_{v}-C_{p} X_{p}+R_{v} X_{v}+R_{p} X_{p}-W_{b} N_{b}-W_{u} N_{u}-W_{s} Y_{s}-W_{x} V_{x}$ 
Restrições de utilização de terra:

$\mathrm{A}_{\mathrm{av}} \mathrm{X}_{\mathrm{v}} \leq \mathrm{T}_{\mathrm{a}}$

Restrições de utilização de mão de obra:

$B_{b v} X_{v}+B_{b p} X_{p}+B_{b f} X_{f}+B_{b m} X_{m}+B_{b h} X_{h}-N_{b} \leq T_{b}$

Restrições relativas à produção vegetal:

$-\mathrm{S}_{\mathrm{qv}} \mathrm{X}_{\mathrm{v}}+\mathrm{Q}_{\mathrm{g}}+\mathrm{Q}_{\mathrm{j}}+\mathrm{Q}_{\mathrm{s}}+\mathrm{Q}_{\mathrm{x}} \leq 0$

Restrições relativas à produção animal:

$-\mathrm{S}_{\mathrm{tp}} \mathrm{X}_{\mathrm{p}}+\mathrm{Q}_{\mathrm{t}}+\mathrm{Q}_{\mathrm{e}}+\mathrm{Q}_{\mathrm{z}} \leq 0$

Restrições relativas às necessidades de nutrientes para os animais:

$\mathrm{F}_{\mathrm{lp}} \mathrm{X}_{\mathrm{p}}-\mathrm{G}_{\mathrm{lj}} \mathrm{Q}_{\mathrm{j}} \leq 0$

Restrições relativas à máxima capacidade de ingestão (animais):

$-\mathrm{I}_{\mathrm{p}} \mathrm{X}_{\mathrm{p}}+\mathrm{H}_{\mathrm{j}} \mathrm{Q}_{\mathrm{j}} \leq 0$

Restrições relativas às necessidades de nutrientes para a família:

$\mathrm{F}_{\mathrm{nh}} \mathrm{X}_{\mathrm{h}}-\mathrm{G}_{\mathrm{ng}} \mathrm{Q}_{\mathrm{g}}-\mathrm{G}_{\mathrm{nt}} \mathrm{Q}_{\mathrm{t}}-\mathrm{G}_{\mathrm{nu}} \mathrm{N}_{\mathrm{u}} \leq 0$

Restrições relativas à máxima capacidade de ingestão (família):

$-\mathrm{I}_{\mathrm{h}} \mathrm{X}_{\mathrm{h}}+\mathrm{H}_{\mathrm{g}} \mathrm{Q}_{\mathrm{g}}+\mathrm{H}_{\mathrm{t}} \mathrm{Q}_{\mathrm{t}}+\mathrm{H}_{\mathrm{u}} \mathrm{N}_{\mathrm{u}} \leq 0$

Restrições relativas ao limite máximo de cada alimento a adquirir para a família:

$\mathrm{O}_{\mathrm{uh}} \mathrm{Z}_{\mathrm{h}}-\mathrm{L}_{\mathrm{u}} \leq 0$

$-1,1 \mathrm{~L}_{\mathrm{u}}+\mathrm{N}_{\mathrm{u}} \leq 0$

Restrições relativas ao limite mínimo de cada alimento a adquirir para a família:

$\mathrm{O}_{\mathrm{uh}} \mathrm{Z}_{\mathrm{h}}-\mathrm{L}_{\mathrm{u}} \leq 0$

$0,9 \mathrm{~L}_{\mathrm{u}}-\mathrm{N}_{\mathrm{u}} \leq 0$ 
Restrição relativa às atividades festivas:

$\mathrm{Y}_{\mathrm{s}}=1$

Restrição relativa aos custos fixos:

$\mathrm{V}_{\mathrm{x}}=1$

Em que as variáveis são:

$\mathbf{N}_{\mathbf{b}}$ - vetor coluna $(b \times 1)$ de mão de obra contratada;

$\mathbf{L}_{\mathbf{u}}$ - vetor coluna $(u \times 1)$ de limite de compra de alimentos para a família;

$\mathbf{N}_{\mathbf{u}}$ - vetor coluna $(\mathrm{u} \times 1)$ de compra de alimentos para a família;

$\mathbf{Q}_{\mathbf{g}}$ - vetor coluna $(\mathrm{g} \times 1)$ de procura de alimentos vegetais para a família;

$\mathbf{Q}_{\mathbf{j}}$ - vetor coluna $(\mathbf{j} \times 1)$ de procura de alimentos vegetais para os animais;

$\mathbf{Q}_{\mathbf{s}}$ - vetor coluna ( $\times 1$ ) de procura de alimentos vegetais para as festividades;

$\mathbf{Q}_{\mathbf{x}}$ - vetor coluna $(x \times 1)$ de procura de alimentos vegetais para venda;

$\mathbf{Q}_{\mathbf{t}}$ - vetor coluna ( $\left.\mathrm{t} \times 1\right)$ de procura de alimentos animais para a família;

$\mathbf{Q}_{\mathbf{z}}$ - vetor coluna $(\mathbf{z} \times 1)$ de procura de alimentos animais para venda;

$\mathbf{Q}_{\mathbf{e}}$ - vetor coluna $(\mathrm{e} \times 1)$ de procura de alimentos animais para as festividades;

$\mathbf{X}_{v}$ - vetor coluna $(v \times 1)$ de atividades produtivas vegetais, em termos de área ocupada;

$\mathbf{X}_{\mathbf{p}}$ - vetor coluna $(p \times 1)$ de atividades produtivas animais, em termos de cabeças;

$\mathbf{X}_{\mathbf{h}}$ - vetor coluna $(\mathrm{h} \times 1)$ de atividades familiares;

$\mathbf{X}_{\mathbf{f}}$ - vetor coluna $(\boldsymbol{f} \times 1)$ de atividades festivas;

$\mathbf{X}_{\mathbf{m}}$ - vetor coluna $(\mathrm{m} \times 1)$ de atividades comunitárias;

$\mathbf{V}_{\mathbf{x}}$ - vetor $(1 \times 1)$ referente aos custos fixos;

$\mathbf{Y}_{\mathbf{s}}$ - vetor $(1 \times 1)$ referente às atividades festivas;

$Z_{h}$ - vetor coluna $(h \times 1)$ de $n^{\circ}$ de pessoas.

E os parâmetros são:

$\mathbf{A}_{\mathrm{av}}$ - matriz $(\mathrm{a} \times \mathrm{v})$ das necessidades de terra, para as atividades vegetais;

$\mathbf{B}_{\mathrm{bv}}{ }^{-}$matriz $(\mathrm{b} \times \mathrm{v})$ de coeficientes input de mão de obra para o setor vegetal;

$\mathbf{B}_{\mathbf{b p}}$ - matriz $(\mathrm{b} \times \mathrm{p})$ de coeficientes input de mão de obra para o setor animal;

$\mathbf{B}_{\mathbf{b f}}$ - matriz $(\mathrm{b} \times \mathrm{f})$ de coeficientes input de mão de obra para as festividades;

$\mathbf{B}_{b \mathbf{b}}$ - matriz $(b \times h)$ de coeficientes input de mão de obra para as atividades familiares;

$\mathbf{B}_{b_{\mathbf{b m}}}$ - matriz $(\mathrm{b} \times \mathrm{m})$ de coeficientes input de mão de obra para atividades comunitárias;

$\mathbf{C}_{\mathrm{v}}$ - vetor linha $(1 \times \mathrm{v})$ de custos das atividades vegetais;

$\mathbf{C}_{\mathbf{p}}$ - vetor linha $(1 \times \mathrm{p})$ de custos das atividades pecuárias;

$F_{1 p}$ - matriz $(I \times p)$ de coeficientes relativos às necessidades mínimas de nutrientes dos animais;

$\mathbf{F}_{n h}$ - matriz $(n \times h)$ de coeficientes relativos às necessidades mínimas de nutrientes da família;

$\mathbf{G}_{\mathrm{ij}}$ - matriz $(\mathbf{I} \times \mathrm{j})$ de coeficientes output de nutrientes dos alimentos para os animais;

$\mathbf{G}_{\mathrm{ng}}$ - matriz $(\mathrm{n} \times \mathrm{g})$ de coeficientes output de nutrientes dos alimentos vegetais (família);

$\mathbf{G}_{\mathrm{nt}}$ - matriz $(\mathrm{n} \times \mathrm{t})$ de coeficientes output de nutrientes dos alimentos animais (família);

$\mathbf{G}_{\mathrm{nu}}$ - matriz $(\mathrm{n} \times \mathrm{u})$ de coeficientes output de nutrientes dos alimentos comprados (família);

$\mathbf{H}_{\mathrm{g}}$ - vetor coluna $(\mathrm{g} \times 1)$ de coeficientes output de matéria seca dos alimentos vegetais (família);

$\mathbf{H}_{\mathrm{t}}$ - vetor coluna $(\mathrm{t} \times 1)$ de coeficientes output de matéria seca dos alimentos animais (família);

$\mathbf{H}_{j}$ - vetor coluna $(\mathrm{j} \times 1)$ de coeficientes output de matéria seca dos alimentos vegetais (animais);

$\mathbf{H}_{\mathbf{u}}$ - vetor coluna $(\mathbf{u} \times 1)$ de coeficientes output de matéria seca dos alimentos adquiridos (família);

$I_{p}$ - vetor linha $(1 \times p)$ de coeficientes relativos à máxima capacidade de ingestão de matéria seca dos animais;

$I_{h}$ - vetor linha $(1 \times h)$ de coeficientes relativos à máxima capacidade de ingestão de matéria seca da família;

$\mathbf{O}_{\mathrm{uh}}$ - matriz $(\mathrm{u} \times \mathrm{h})$ de coeficientes relativos às necessidades de compra de alimentos; 
$\mathbf{S}_{\mathrm{qv}}$ - matriz $(q \times v)$ de coeficientes relacionando a produção de alimentos com as atividades vegetais;

$\mathbf{S}_{\mathrm{tp}}$ - matriz $(\mathrm{t} \times \mathrm{p})$ de coeficientes relacionando a produção de alimentos com as atividades animais;

$\mathbf{T}_{m}$ - vetor coluna $(m \times 1)$ de disponibilidades de fatores próprios, terra, $T_{a}$; mão de obra $T_{b}$;

$\mathbf{W}_{\mathbf{b}}$ - vetor linha $(1 \times$ b) de preços de aquisição de mão de obra;

$\mathbf{W}_{\mathbf{u}}$ - vetor linha $(1 \times \mathbf{u})$ de preços de aquisição de alimentos para a família;

$\mathbf{W}_{\mathbf{x}}$ - escalar referente aos custos fixos;

$\mathbf{W}_{\mathbf{s}}$ - escalar referente aos custos com as festividades.

A função objetivo indica que a família maximiza o bem-estar dos agregados familiares. Assim a função objetivo maximiza:

Disponibilidades financeiras das famílias para as outras despesas familiares $=$ Receitas das atividades agrícolas - Custos das atividades agrícolas - Custos com as festividades Custos com a alimentação humana - Custos fixos

As restrições (1) definem a utilização da terra. A terra encontra-se desagregada por tipo de utilização. Cada equação reflete as necessidades de terra das várias atividades de produção vegetal.

As restrições (2) referem-se à utilização de mão de obra para as diferentes atividades: vegetais, animais, familiares, comunitárias e festivas. São elaboradas considerando separadamente a mão de obra masculina e a mão de obra feminina.

As restrições (3) e (4) fazem o balanço entre a produção (vegetal ou animal) e os diferentes usos da mesma.

As restrições (5) e (6) referem-se à alimentação animal. As restrições (5) garantem a satisfação das exigências nutritivas mínimas dos animais $\left(F_{1 p} X_{p}\right)$, pelos alimentos produzidos $\left(\mathrm{G}_{\mathrm{lj}} \mathrm{Q}_{\mathrm{j}}\right)$. As restrições (6) asseguram que o consumo de matéria seca, dado pela procura (consumo) de alimentos produzidos $\left(\mathrm{H}_{\mathrm{j}} \mathrm{Q}_{\mathrm{j}}\right)$ não excede a capacidade máxima de ingestão de matéria seca dos animais. Há um conjunto destas restrições para cada espécie animal.

As restrições (7) e (8)) referem-se à alimentação da família. As restrições (7) garantem a satisfação das exigências nutritivas mínimas $\left(F_{n h} X_{h}\right)$, pelos alimentos produzidos de origem vegetal $\left(G_{n g} Q_{g}\right)$, de origem animal $\left(G_{n t} Q_{t}\right)$ e pelos alimentos comprados $\left(G_{n u} N_{u}\right)$. As restrições (8) asseguram que o consumo de matéria seca, dado pela procura (consumo) de alimentos produzidos de origem vegetal $\left(\mathrm{H}_{\mathrm{g}} \mathrm{Q}_{\mathrm{g}}\right)$, de origem animal $\left(\mathrm{H}_{\mathrm{t}} \mathrm{Q}_{\mathrm{t}}\right)$ e de alimentos comprados $\left(\mathrm{H}_{\mathrm{u}} \mathrm{N}_{\mathrm{u}}\right)$ não excede a capacidade máxima de ingestão de matéria seca da família. As restrições (9) asseguram um limite máximo para a aquisição de alimentos para a família, de acordo com a dieta alimentar da mesma. As restrições (10) asseguram um limite mínimo para a aquisição de alimentos para a família, de acordo com a dieta alimentar da mesma.

As restrições (11) e (12) servem para incluir na função objetivo, respetivamente, os gastos com as festividades e os custos fixos.

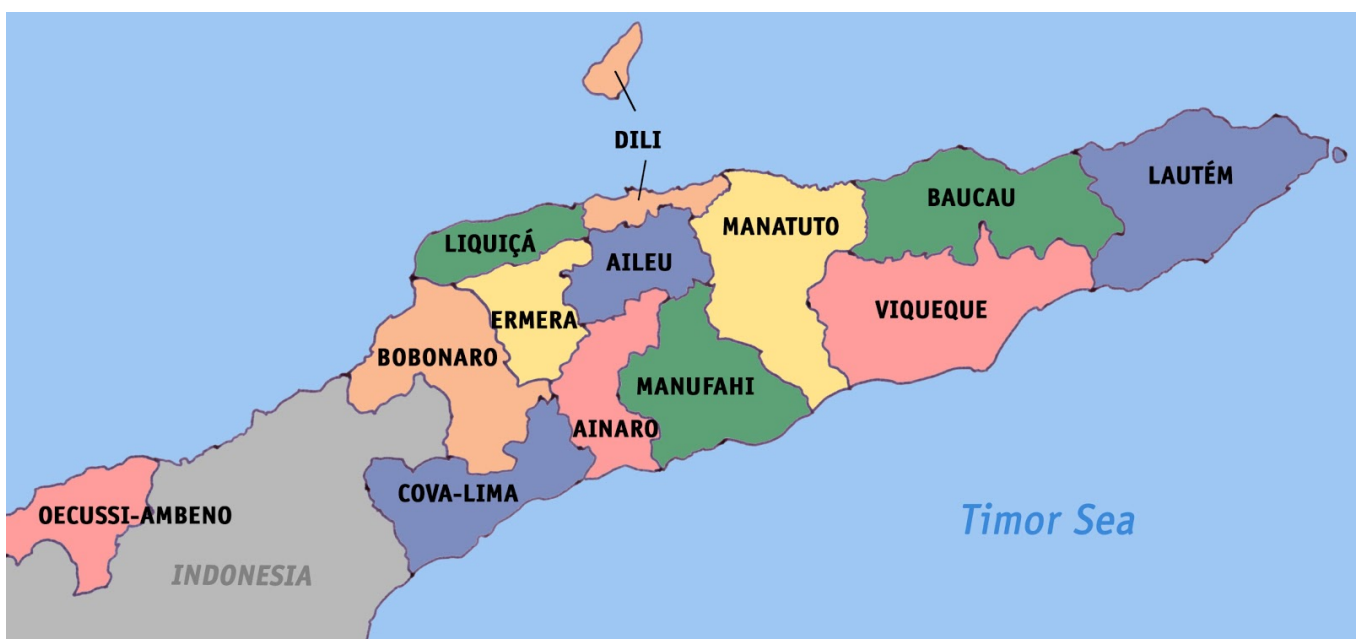

Figura 1 - Mapa dos distritos de Timor-Leste

Fonte: https://rinaldimunir.files.wordpress.com/2019/07/1798794_timor-lestedistrick.png 
Para atingir os objetivos enunciados para este estudo, foi necessário selecionar a área de estudo, representativa da produção agrícola e pecuária, dada a impossibilidade temporal e de recursos materiais de incidir sobre todo o território. Os distritos selecionados, todos nas zonas Oeste e Central de Timor-Leste e correspondendo a um contínuo territorial Leste-Oeste e Norte Sul, foram Ailéu, Ermera, Bobonaro e Covalima (Figura 1). O distrito de Ermera concentra a maior parte da área e da produção de café (Belo, 2017). O distrito de Bobonaro tem uma das maiores várzeas de produção de arroz (Rendes, 2013). O distrito de Covalima é desde há longo tempo conhecido pelo seu potencial para a produção pecuária. O distrito de Ailéu se beneficia do fato de estar perto do maior distrito urbano, Díli, ao especializar-se na produção de culturas hortícolas. Estes distritos representam as principais atividades econômicas: o café em Ermera, a produção pecuária em Covalima, o arroz em Bobonaro e as hortícolas em Ailéu.

A informação qualitativa utilizada teve origem na observação participante e Action Research, enquanto a informação quantitativa provém de bases de dados e questionários.

A recolha de dados primários foi feita junto aos agregados familiares selecionados, tendo em conta principalmente as características do sistema de produção. Foram recolhidos presencialmente, por questionário, com o propósito de identificar e caracterizar os sistemas de agricultura praticados e o modo de vida dos agregados familiares, pelo qual incluiu uma recolha de dados sobre as atividades produtivas, reprodutivas e comunitárias. A informação obtida por questionário permitiu, também, identificar as variáveis que diferenciam os agregados familiares em termos de atividades, recursos, tecnologias e objetivos, para que o modelo de PLE pudesse incorporar as especificidades de cada sistema de agricultura.

Foi usada a técnica de amostragem não probabilística, por não ser possível especificar a probabilidade de um sujeito pertencer à população. Dentro desta, foi aplicada a técnica de amostragem não probabilística criterial pelo fato de o investigador ter selecionado o sistema de agricultura do agregado familiar a partir da amostra de agricultores inquiridos pelo questionário realizado em 2009/2010 por Rubzen et al. (2010), seguindo determinados critérios. Foram, assim, selecionados oito agregados familiares representativos em cada um dos quatro distritos da área de estudo, dentro da combinação modal, para a seguinte ordenação de critérios: sistema de agricultura, área total, gênero do chefe da família, dimensão do agregado, educação, número de animais e número de culturas. A amostra final dos agricultores ficou constituída por 30 agregados familiares dos quatro distritos, menos dois que os inicialmente previstos. Os dois agregados familiares não inquiridos pertenciam ao distrito de Ermera e Aileu e não foram localizados durante o trabalho de campo, não se tendo procedido à sua substituição por restrições de ordem temporal.

\section{IMPLEMENTAÇÃO EMPÍRICA DOS MODELOS DE PLE}

Na construção dos modelos de PLE, utilizaram-se os valores médios obtidos por distrito, para as principais variáveis que caracterizam as produções agrícola e pecuária, o ciclo de vida doméstico e a inserção sociocultural na comunidade. Usar estes valores - e não os valores observados para cada um dos agregados familiares inquiridos - ocorreu pelo fato de existirem algumas situações com respostas omissas às perguntas do questionário.

A área cultivada por família para culturas vegetais anuais é geralmente pequena, com uma média de 3,57 hectares por agregado familiar no município de Aileu; em Ermera, a média é 4,21 hectares; em Bobonaro, é de 2,69 hectares, e em Covalima, é de 1,94 hectares. As atividades de produção vegetal mais comuns nestes municípios são a abóbora, o arroz, a batata-doce, o café, a cebola, a cenoura, o feijão, o feijão-mungo, a mandioca, a mostarda e o repolho, que constituem os alimentos básicos para as famílias. O café e o arroz ocupam áreas próprias, sendo cultivados em contínuo, sempre na mesma parcela. Na modelação das produções vegetais, assumiu-se que os alimentos produzidos se encontram disponíveis para satisfazer as necessidades nutritivas dos animais e do agregado familiar, além de ser o contributo para as festividades e a eventual venda. 
As principais atividades pecuárias consistem em produção de bovinos, porcinos, caprinos e galinhas. Cada unidade pecuária, definida considerando o encabeçamento médio da amostra em cada distrito, inclui os machos, as fêmeas e as crias nascidas e criadas, admitindo uma taxa de mortalidade média de $20 \%$. Os animais produzidos destinam-se a venda e autoconsumo, e às festividades. Na sua modelação, considera-se que a produção pecuária produz animais e ovos, disponíveis para satisfazer as necessidades nutritivas do agregado familiar, para contribuir para as festividades e para eventual venda.

As necessidades alimentares dos animais foram calculadas para o peso médio de cada espécie por fêmea reprodutora, incluindo esta às correspondentes necessidades dos animais jovens; note-se que as necessidades alimentares foram modeladas separadamente para cada uma das espécies. Os recursos alimentares são os provenientes das pastagens próprias/comunitárias e também da compra no mercado de alimentos para os animais.

As disponibilidades de mão de obra destinam-se a satisfazer as tarefas de produção agrícola, domésticas do agregado familiar e das atividades comunitárias e festivas. Foram calculadas considerando a disponibilidade do casal em 365 dias por ano, dos membros mais velhos em 50\% e dos jovens em 25\%. Foram divididas por gênero, dado que algumas das tarefas agrícolas e pecuárias, domésticas e comunitárias, e festivas são executadas, especificamente, por homens ou por mulheres.

$\mathrm{Na}$ alimentação humana, os consumos médios diários de energia e proteínas considerados foram de, respetivamente, $2.100 \mathrm{kcal}$ e 50 gramas. Aos jovens e às crianças, foram aplicados os pesos de 0,75 e 0,50. Para satisfazer as necessidades alimentares, foi calculado o cabaz médio diário de alimentos consumidos por um indivíduo adulto (cabaz indicativo), com base nos dados disponíveis no Timor-Leste: Poverty in a Young Nation (Direcção Nacional de Estatística, 2008). De modo a flexibilizar as quantidades deste cabaz no modelo, admitiu-se uma variação de $20 \%$ em torno do cabaz indicativo. No modelo, considera-se que as necessidades alimentares do agregado familiar são satisfeitas através de dois grupos de atividades: 1) alimentos que são produzidos pelo agregado familiar e 2) alimentos que, pela importância na alimentação humana, a sua compra é individualizada no modelo. Para além dos alimentos produzidos e disponibilizados para alimentação humana referidos, a satisfação das necessidades alimentares do agregado familiar é feita também através de outros alimentos comprados no exterior. Estes estão incluídos numa atividade global de um cabaz de alimentos comprados no exterior de acordo com Direcção Nacional de Estatística (2008) e que disponibiliza energia e proteína, em cada uma das restrições correspondentes. Assumese, assim, não existir carência alimentar na satisfação das necessidades básicas alimentares e os agregados familiares têm acesso a um cabaz diversificado de alimentos de acordo com o distrito a que pertencem.

As atividades domésticas familiares consideradas foram: cuidar dos filhos; higiene pessoal; cozinhar; limpar casa; ida ao bazar; recolher lenha; arranjar a roupa e ir buscar água, e atividades essencialmente consumidoras de mão de obra, para as quais, no correspondente cálculo das necessidades dos agregados familiares, nos distritos estudados, foi considerado um ponderador da disponibilidade diária para as mulheres de 14 horas e, para os homens, de12 horas, durante 365 dias por ano.

As atividades comunitárias consideradas foram dia da independência; limpeza de estrada; ida à Igreja; trabalhos na aldeia; cuidados de saúde, e participação na educação. No cálculo das necessidades em mão de obra destas atividades foram utilizados os mesmos pressupostos que nas atividades domésticas familiares que apenas consomem mão de obra

As festividades consideradas foram as nomeadas pelas famílias inquiridas em cada distrito: casamento, batizado, aniversário, funeral, desluto e cultura (casa tradicional). O exercício e a participação nestas festividades representam momentos que permitem à família estreitar laços com o grupo familiar a que pertence, com a aldeia e a comunidade, reforçando a coesão interna do grupo, o sentimento de pertença e a segurança pessoal e dos recursos. As festividades consomem um conjunto de recursos dos agregados familiares, quer em termos de mão de obra, quer de bens materiais, incluindo montantes em dinheiro. Relativamente aos custos e receitas com as atividades festivas, consideraram- 
se os dados publicados pela Direção Geral de Estatística resultantes da Timor-Leste survey of living standarts 2014-2015 recolhidos para uma amostra de agricultores dos quatro distritos em estudo.

Os custos fixos consideraram o número médio de utensílios por agricultor e distrito (catana, machado, enxada, ancinho, foice e alavanca) e a respetiva vida útil.

Os preços utilizados, nos modelos de PLE e no cálculo do custo do cabaz de bens consumidos pelas famílias, foram recolhidos em várias fontes: mercados locais, agricultores, Ministério de Agricultura e Pescas, e Direção Nacional de Estatística.

A função objetivo maximiza as disponibilidades financeiras para as despesas familiares que não são contempladas nos modelos - educação dos filhos, saúde, vestuário, higiene pessoal e deslocações, entre outras, sendo representada do modo seguinte:

Receitas das atividades agrícolas e pecuárias - Custos das atividades agrícolas - Custos com as festividades - Custos com a alimentação humana.

\section{RESULTADOS}

Os modelos foram calibrados e validados para garantir, na medida do possível, que os modelos de base e os seus resultados sejam uma representação tão próxima quanto o desejável da situação real e observada dos agregados familiares.

A validação de um modelo é normalmente feita comparando os resultados obtidos pelo modelo base com os resultados observados na recolha de dados. Neste caso, através da comparação das principais variáveis em termos de produção animal e vegetal, domésticas, comunitárias e festividades, recursos utilizados e resultados econômicos. Se os desvios forem inferiores a $15 \%$, o modelo base pode considerar-se calibrado e validado, ou seja, com uma boa representação da realidade a estudar (Hazell \& Norton, 1986).

Devido às dificuldades logísticas e financeiras, não foi possível voltar aos agregados familiares inquiridos para fazer a calibração e validação dos resultados obtidos pelos modelos. Toda a calibração e validação dos modelos e dos seus resultados base foi feita em confronto com os dados recolhidos, com a experiência de trabalho de campo dos autores junto a agregados familiares rurais de Timor-Leste e com a opinião e ajuda de investigadores com experiência neste tipo de modelos e conhecimento da realidade timorense. Desse confronto, verifica-se que os resultados obtidos para as variáveis dos modelos de base de PLE, seguidamente analisados, são muito semelhantes aos observados na realidade, com um desvio absoluto percentual menor que $15 \%$.

Uma síntese dos principais resultados base para os quatro distritos é apresentada no Quadro 1. A sua análise evidencia um pendor maior de produção pecuária no distrito da zona Oeste, Covalima, e, como consequência, melhores resultados econômicos. Apesar de o distrito de Ermera apresentar uma área superior, tal característica não se traduz numa geração de rendimento maior, o que leva a dizer que a cultura do café, por si só, não é, nas condições tecnológicas e de manejo atuais, um fator diferenciador do rendimento dos agregados familiares.

Apesar de as festividades não representarem uma proporção muito elevada quer das receitas, quer da margem líquida, os valores observados são maiores para os distritos da zona central em comparação com os distritos da zona oeste.

A contribuição dos alimentos produzidos para o fornecimento de energia e proteína varia com a composição da produção vegetal e a área de cada agregado familiar. Os agregados que produzem arroz (Bobonaro) apresentam valores substancialmente mais elevados do que os outros distritos. Nestes, Ailéu mostra os níveis menores de autossuficiência, quer devido à combinação de culturas na rotação, quer à dimensão a elas afeta. O peso monetário do autoconsumo é relativamente modesto quando expresso em termos das receitas da família.

No uso da mão de obra familiar disponível, verifica-se que os distritos da zona Oeste, com maior produção pecuária, apresentam níveis de utilização deste fator superiores aos distritos da zona central. Nas atividades vegetais, não se evidenciam diferenças no uso da mão de obra, à exceção do distrito de Ermera com dimensões de exploração superiores. 
Na comparação dos custos da alimentação por adulto com a linha da pobreza para a alimentação calculada pelo TLSLS (Direcção Nacional de Estatística, 2016), verifica-se que os valores estão próximos, com um desvio absoluto percentual inferior aos $15 \%$, recomendado pela literatura (Hazell \& Norton, 1986), à exceção do distrito de Ermera, cujo valor está ligeiramente acima $(16,4 \%)$.

Quadro 1 - Síntese dos Principais Resultados Base por Distrito

\begin{tabular}{|c|c|c|c|c|}
\hline Distrito & Ailéu & Ermera & Bobonaro & Covalima \\
\hline Atividades Vegetais (Área Total na Rotação) & 1,57 & 1,71 & 0,90 & 1,09 \\
\hline Atividades Vegetais na Rotação & $\begin{array}{c}\text { Cebola, } \\
\text { Cenoura, Feijão, } \\
\text { Repolho }\end{array}$ & $\begin{array}{c}\text { Abóbora, } \\
\text { Batata-Doce, } \\
\text { Feijão, Milho, } \\
\text { Mostarda, } \\
\text { Repolho }\end{array}$ & $\begin{array}{c}\text { Abóbora, } \\
\text { Batata-Doce, } \\
\text { Feijão, Milho, } \\
\text { Repolho }\end{array}$ & $\begin{array}{l}\text { Feijão-Mungo, } \\
\text { Milho, Mostarda }\end{array}$ \\
\hline Atividades Vegetais (ha Café) & 1,75 & 2,0 & 0,0 & 0,75 \\
\hline Atividades Vegetais (ha Arroz) & 0,0 & 0,0 & 1,58 & 0,0 \\
\hline Atividades Vegetais (ha Mandioca) & 0,25 & 0,50 & 0,20 & 0,10 \\
\hline Atividades Pecuárias (Espécie e $N^{\circ}$ de Animais) & $\begin{array}{c}\text { Galinhas (11), } \\
\text { Porcos (3), } \\
\text { Cabras (4), } \\
\text { Vacas (2) }\end{array}$ & $\begin{array}{c}\text { Galinhas (10), } \\
\text { Porcos (4), } \\
\text { Cabras (3), } \\
\text { Vacas (2) }\end{array}$ & $\begin{array}{c}\text { Galinhas (13), } \\
\text { Porcos (9), } \\
\text { Cabras (9), } \\
\text { Vacas (7) }\end{array}$ & $\begin{array}{c}\text { Galinhas (17), } \\
\text { Porcos (15), } \\
\text { Cabras (6), Vacas } \\
\text { (6) }\end{array}$ \\
\hline M.O. usada em Atividades Vegetais (\%) & 14,2 & 19,4 & 12,5 & 12,7 \\
\hline M.O. usada em Atividades Pecuárias (\%) & 10,8 & 11,7 & 26,0 & 27,7 \\
\hline M.O. usada em Atividades Familiares (\%) & 37,3 & 31,1 & 31,6 & 34,0 \\
\hline M.O. em Atividades Comunitárias/Festivas (\%) & 2,3 & 3,5 & 4,0 & 3,0 \\
\hline Tempo de lazer (\%) & 31,6 & 17,5 & 21,7 & 18,2 \\
\hline $\begin{array}{l}\text { Contributo da Produção Própria para a Energia da Alimentação Humana } \\
(\%)\end{array}$ & 23,8 & 40,4 & 62,3 & 34,0 \\
\hline $\begin{array}{l}\text { Contributo da Produção Própria para a Proteína da Alimentação Humana } \\
\qquad(\%)\end{array}$ & 22,9 & 47,4 & 58,7 & 36,7 \\
\hline Contributo das Atividades Vegetais para a Receita da Família (\%) & 58,2 & 57,3 & 59,8 & 31,2 \\
\hline Contributo das Atividades Pecuárias para a Receita da Família (\%) & 41,8 & 42,7 & 40,2 & 68,8 \\
\hline Peso das Obrigações Sociais na Margem Líquida sem Festividades (\%) & 26,2 & 18,5 & 4,9 & 4,8 \\
\hline Peso do Autoconsumo na Receita da Família (\%) & 12,0 & 13,5 & 10,2 & 6,7 \\
\hline Custo diário da alimentação por membro do agregado adulto & 0,91 & 0,86 & 0,83 & 0,84 \\
\hline Linha da pobreza da alimentação & 0,80 & 0,72 & 0,83 & 0,86 \\
\hline
\end{tabular}

Fonte: Modelos de PLE (Deus, 2018).

A análise dos resultados referentes à economia dos agregados familiares por distrito e classes de dimensão trata das características da produção agrícola (vegetal e pecuária), da alimentação, da utilização da mão de obra familiar, além de tratar da formação do rendimento agrícola e da sua consequência no bem-estar dos agregados familiares.

Relativamente às produções vegetais, para os distritos onde as explorações apresentam duas rotações, verifica-se que, à exceção de Covalima, são escolhidas ambas, embora a rotação com abóbora tenha uma área sempre menor. 
No que diz respeito aos animais, o modelo escolheu o encabeçamento máximo que os agricultores possuem.

No Quadro 2, pode verificar-se que, por distrito, os níveis de autossuficiência alimentar aumentam com a área da exploração. $O$ distrito de Ailéu é o que apresenta níveis mais baixos de autossuficiência alimentar e o de Bobonaro, os níveis mais elevados. No caso de Ailéu, esta situação tem a ver com a combinação de atividades vegetais produzida, essencialmente hortícolas, e no caso de Bobonaro, a autossuficiência em arroz explica muito do valor elevado observado para este distrito. O custo diário da alimentação per capita, obtido pelo modelo, apresenta valores próximos aos calculados para a componente da alimentação da linha da pobreza. O desvio percentual é inferior aos 15\%, como recomendado pela literatura (Hazell \& Norton, 1986).

Quadro 2 - Níveis de autossuficiência alimentar por distrito e por classes de área

\begin{tabular}{|c|c|c|c|c|c|c|c|c|c|c|c|c|}
\hline \multirow{2}{*}{ Item } & \multicolumn{3}{|c|}{ Ailéu } & \multicolumn{3}{|c|}{ Ermera } & \multicolumn{3}{|c|}{ Bobonaro } & \multicolumn{3}{|c|}{ Covalima } \\
\hline & 1 ha & 2,5 ha & 7,5 ha & 1 ha & 2,5 ha & 7,5 ha & 1 ha & 2,5 ha & 7,5 ha & 1 ha & 2,5 ha & 7,5 ha \\
\hline Necessidade total de energia & 3833 & 4407 & 4982 & 3833 & 3833 & 4407 & 3833 & 3833 & 3833 & 3833 & 3833 & 3833 \\
\hline $\begin{array}{l}\text { Total de alimentos produção } \\
\text { própria }\end{array}$ & 419 & 509 & 1893 & 1456 & 2002 & 2233 & 2262 & 2812 & 2922 & 1447 & 1557 & 1557 \\
\hline $\begin{array}{l}\text { Percentagem de alimentos } \\
\text { de produção própria }\end{array}$ & 10,9 & 11,6 & 38,0 & 38,0 & 52,2 & 50,7 & 59,0 & 73,4 & 76,2 & 37,8 & 40,6 & 40,6 \\
\hline $\begin{array}{l}\text { Necessidade total de } \\
\text { proteína }\end{array}$ & 91251 & 104939 & 118627 & 91251 & 91251 & 104939 & 91251 & 91251 & 91251 & 91251 & 91251 & 91251 \\
\hline $\begin{array}{l}\text { Total de alimentos produção } \\
\text { própria }\end{array}$ & 13633 & 16476 & 51295 & 18790 & 33459 & 40064 & 49059 & 64643 & 73134 & 59717 & 60644 & 60644 \\
\hline $\begin{array}{l}\text { Percentagem de alimentos } \\
\text { de produção própria }\end{array}$ & 14,9 & 15,7 & 43,2 & 20,6 & 36,7 & 38,2 & 53,8 & 70,8 & 80,1 & 65,4 & 66,5 & 66,5 \\
\hline $\begin{array}{l}\text { Custo diário da alimentação } \\
\text { por pessoa }\end{array}$ & 0,93 & 0,93 & 0,87 & 0,72 & 0,69 & 0,71 & 0,86 & 0,82 & 0,80 & 0,86 & 0,84 & 0,84 \\
\hline $\begin{array}{l}\text { Linha da pobreza da } \\
\text { alimentação }\end{array}$ & 0,80 & 0,80 & 0,80 & 0,72 & 0,72 & 0,72 & 0,83 & 0,83 & 0,83 & 0,86 & 0,86 & 0,86 \\
\hline $\begin{array}{l}\text { Desvio percentual dos } \\
\text { custos da alimentação da } \\
\text { linha da pobreza da } \\
\text { alimentação }\end{array}$ & 14,4 & 14,2 & 8,7 & 0,0 & $-4,9$ & $-1,8$ & 3,4 & $-0,9$ & $-3,2$ & 0,7 & $-1,5$ & $-1,5$ \\
\hline
\end{tabular}

Fonte: Modelos de PLE (Deus, 2018).

Quanto à ocupação da mão de obra, o seu uso na atividade agrícola aumenta com a dimensão das explorações, sendo que os homens trabalham mais nas atividades agrícolas e as mulheres, mais nas tarefas domésticas. O tempo disponível para outras atividades, nas quais se inclui o lazer, é maior para as mulheres do que para os homens, com exceção do distrito de Ermera e de algumas classes de área do distrito de Bobonaro e Covalima. Uma parte da explicação para esta situação é em razão de as disponibilidades familiares de mão de obra feminina serem superiores às de mão de obra masculina, principalmente pelo fato de haver uma idosa feminina a fazer parte de todos os agregados familiares considerados. Excluindo a disponibilidade da idosa feminina, as mulheres ficariam com menos tempo de lazer do que os homens e, para as explorações de maior dimensão de Bobonaro e Covalima, haveria um déficit de mão de obra feminina. É preciso também ter em atenção que, no cálculo das disponibilidades de mão de obra, foram contabilizados todos os dias do ano. Se os fins de semana forem retirados das disponibilidades familiares de mão de obra, verifica-se: 1) para homens (H) e mulheres (M), uma descida da proporção dos dias disponíveis para outro tipo de atividades; 2) para os homens, as explorações grandes de Ailéu e Ermera, e as explorações médias de Covalima passam a ter um déficit de mão de obra masculina e o déficit já existente nas explorações grandes no distrito de Bobonaro e Covalima aumenta; 3 ) para as mulheres, somente as explorações grandes de Covalima passam a ter um déficit de mão de obra feminina (Quadros 3 e 4). 
Quadro 3 - Ocupação da mão de obra (percentagem da disponibilidade total) - distritos de Ailéu e Ermera

\begin{tabular}{|c|c|c|c|c|c|c|c|c|c|c|c|c|}
\hline \multirow{3}{*}{ Item } & \multicolumn{6}{|c|}{ Ailéu } & \multicolumn{6}{|c|}{ Ermera } \\
\hline & 1 ha & 2,5 ha & 7,5 ha & 1 ha & 2,5 ha & 7,5 ha & 1 ha & 2,5 ha & 7,5 ha & 1 ha & 2,5 ha & 7,5 ha \\
\hline & $\mathbf{H}$ & $\mathbf{H}$ & H & M & M & M & $\mathbf{H}$ & $\mathbf{H}$ & $\mathbf{H}$ & M & M & M \\
\hline Mão de obra atividades vegetais & 6 & 39 & 42 & 2 & 7 & 20 & 6 & 15 & 40 & 3 & 7 & 20 \\
\hline Mão de obra atividades pecuárias & 17 & 17 & 15 & 3 & 2 & 3 & 14 & 17 & 22 & 3 & 3 & 3 \\
\hline Mão de obra atividades domésticas & 29 & 27 & 24 & 47 & 44 & 41 & 14 & 14 & 13 & 45 & 45 & 42 \\
\hline Mão de obra atividades comunitárias & 3,1 & 3 & 2,6 & 2,1 & 1,9 & 1,8 & 4,1 & 4,1 & 3,8 & 2,5 & 2,5 & 2,3 \\
\hline Mão de obra atividades festivas & 0,3 & 0,3 & 0,2 & 0,2 & 0,2 & 0,1 & 0,4 & 0,4 & 0,4 & 0,3 & 0,3 & 0,3 \\
\hline Consumo total de mão de obra & 55,9 & 61 & 81,1 & 54,7 & 55,4 & 65,4 & 38,7 & 51,6 & 79,3 & 53,9 & 57,7 & 68,2 \\
\hline Disponibilidade de mão de obra familiar & 100 & 100 & 100 & 100 & 100 & 100 & 100 & 100 & 100 & 100 & 100 & 100 \\
\hline Disponibilidade de mão de obra contratada & 0,0 & 0 & 0,0 & 0,0 & 0,0 & 0,0 & 0,0 & 0,0 & 0,0 & 0,0 & 0,0 & 0,0 \\
\hline $\begin{array}{l}\text { Disponibilidade de mão de obra para outras } \\
\text { atividades }\end{array}$ & 44,1 & 39 & 18,9 & 45,3 & 44,6 & 34,6 & 61,3 & 48,4 & 20,7 & 46,1 & 42,3 & 31,8 \\
\hline $\begin{array}{l}\text { Disponibilidade da mão de obra para outras } \\
\text { atividades excluindo a idosa feminina }\end{array}$ & & & & 23,5 & 24,4 & 12,8 & & & & 24,6 & 19,2 & 7,0 \\
\hline $\begin{array}{l}\text { Disponibilidade de mão de obra para outras } \\
\text { atividades excluindo os fins de semana }\end{array}$ & 33,5 & 25,1 & $-3,6$ & 42,3 & 40,0 & 24,9 & 51,6 & 33,6 & $-5,7$ & 42,6 & 37,2 & 21,4 \\
\hline
\end{tabular}

Fonte: Modelos de PLE (Deus, 2018).

Quadro 4. Ocupação da mão de obra (percentagem da disponibilidade total) - distritos Bobonaro e Covalima

\begin{tabular}{|c|c|c|c|c|c|c|c|c|c|c|c|c|}
\hline \multirow{3}{*}{ Item } & \multicolumn{6}{|c|}{ Bobonaro } & \multicolumn{6}{|c|}{ Covalima } \\
\hline & $1 \mathrm{ha}$ & 2,5 ha & 7,5 ha & 1 ha & 2,5 ha & 7,5 ha & 1 ha & 2,5 ha & 7,5 ha & 1 ha & 2,5 ha & 7,5 ha \\
\hline & $\mathrm{H}$ & $\mathrm{H}$ & $\mathrm{H}$ & M & M & M & $\mathrm{H}$ & $\mathrm{H}$ & $\mathrm{H}$ & M & M & M \\
\hline Mão de obra atividades vegetais & 7 & 17 & 50 & 3 & 8 & 25 & 9 & 22 & 67 & 5 & 12 & 37 \\
\hline Mão de obra atividades pecuárias & 23 & 30 & 44 & 3 & 4 & 4 & 29 & 30 & 46 & 4 & 4 & 5 \\
\hline Mão de obra atividades domésticas & 20 & 20 & 20 & 46 & 46 & 46 & 24 & 24 & 24 & 48 & 48 & 48 \\
\hline Mão de obra atividades comunitárias & 4,8 & 4,8 & 4,8 & 3,4 & 3,4 & 3,4 & 3,1 & 3,1 & 3,1 & 3,1 & 3,1 & 3,1 \\
\hline Mão de obra atividades festivas & 0,4 & 0,4 & 0,4 & 0,3 & 0,3 & 0,3 & 0,3 & 0,3 & 0,3 & 0,2 & 0,2 & 0,2 \\
\hline Consumo total de mão de obra & 55,1 & 71,3 & 118,6 & 56,5 & 62,3 & 79,4 & 65,6 & 79,4 & 140,5 & 59,7 & 67,3 & 92,8 \\
\hline $\begin{array}{l}\text { Disponibilidade de mão de obra } \\
\text { familiar }\end{array}$ & 100,0 & 100,0 & 84,4 & 100,0 & 100,0 & 100,0 & 100,0 & 100,0 & 71,2 & 100,0 & 100,0 & 100,0 \\
\hline $\begin{array}{l}\text { Disponibilidade de mão de obra } \\
\text { contratada }\end{array}$ & 0,0 & 0,0 & 15,6 & 0,0 & 0,0 & 0,0 & 0,0 & 0,0 & 28,8 & 0,0 & 0,0 & 0,0 \\
\hline $\begin{array}{l}\text { Disponibilidade de mão de obra para } \\
\text { outras atividades }\end{array}$ & 44,9 & 28,7 & 0,0 & 43,5 & 37,7 & 20,6 & 34,4 & 20,6 & 0,0 & 40,3 & 32,7 & 7,2 \\
\hline $\begin{array}{l}\text { Disponibilidade da mão de obra para } \\
\text { outras atividades, excluindo a idosa } \\
\text { feminina }\end{array}$ & & & & 20,9 & 12,8 & $-11,2$ & & & & 16,4 & 5,8 & $-29,9$ \\
\hline $\begin{array}{l}\text { Disponibilidade de mão de obra para } \\
\text { outras atividades, excluindo os fins de } \\
\text { semana }\end{array}$ & 30,9 & 8,2 & $-57,9$ & 39,5 & 31,4 & 7,4 & 17,8 & $-1,4$ & $-86,9$ & 35,6 & 25,0 & $-10,7$ \\
\hline
\end{tabular}

Fonte: Modelos de PLE (Deus, 2018).

O Quadro 5 resume o resultado econômico, por distrito e por classes de área, de cada uma das explorações agrícolas consideradas. À medida que a dimensão das explorações aumenta, a proporção das receitas provenientes da produção vegetal também aumenta. Com exceção do distrito de Bobonaro, em que dominam sempre as receitas provenientes 
da produção vegetal devido à produção de arroz, nos outros distritos, nas explorações pequenas ( $1 \mathrm{ha}$ ), prevalecem as receitas da produção pecuária, enquanto nas explorações médias ( $2,5 \mathrm{ha})$ e grandes (7,5 ha), imperam as receitas da produção vegetal. Como esperado à medida que a dimensão aumenta, a proporção dos custos com a alimentação na receita total diminui.

Quadro 5 - Receitas, custos e margem líquida por distrito e classe de dimensão

\begin{tabular}{|c|c|c|c|c|c|c|c|c|c|c|c|c|}
\hline & \multicolumn{3}{|c|}{ Ailéu } & \multicolumn{3}{|c|}{ Ermera } & \multicolumn{3}{|c|}{ Bobonaro } & \multicolumn{3}{|c|}{ Covalima } \\
\hline & 1 ha & 2,5 ha & 7,5 ha & 1 ha & 2,5 ha & 7,5 ha & 1 ha & 2,5 ha & 7,5 ha & 1 ha & 2,5 ha & 7,5 ha \\
\hline $\begin{array}{l}\text { Receitas da venda da produção } \\
\text { vegetal }\end{array}$ & 463 & 1313 & 4386 & 246 & 947 & 3609 & 1491 & 4545 & 15118 & 910 & 2775 & 9111 \\
\hline $\begin{array}{l}\text { Receitas da venda da produção } \\
\text { animal }\end{array}$ & 887 & 934 & 933 & 889 & 938 & 1125 & 1029 & 1428 & 1897 & 1379 & 1428 & 2146 \\
\hline $\begin{array}{l}\text { Receitas do autoconsumo da } \\
\text { produção vegetal }\end{array}$ & 196 & 335 & 564 & 302 & 419 & 477 & 642 & 770 & 800 & 404 & 414 & 440 \\
\hline $\begin{array}{l}\text { Receitas do autoconsumo da } \\
\text { produção animal }\end{array}$ & 10 & 11 & 13 & 8 & 8 & 9 & 7 & 7 & 7 & 7 & 7 & 7 \\
\hline Receitas totais da agropecuária & 1556 & 2594 & 5896 & 1445 & 2312 & 5220 & 3169 & 6750 & 17823 & 2700 & 4624 & 11704 \\
\hline $\begin{array}{l}\text { Custos com compras para a } \\
\text { produção agrícola }\end{array}$ & 13 & 33 & 100 & 10 & 25 & 58 & 121 & 302 & 1195 & 46 & 114 & 1266 \\
\hline $\begin{array}{l}\text { Custos com compras para a } \\
\text { produção pecuária }\end{array}$ & 57 & 0 & 0 & 0 & 0 & 0 & 0 & 0 & 0 & 0 & 0 & 0 \\
\hline $\begin{array}{l}\text { Custos do autoconsumo da } \\
\text { produção pecuária }\end{array}$ & 42 & 155 & 83 & 90 & 99 & 99 & 114 & 137 & 121 & 88 & 97 & 124 \\
\hline Custos Fixos & 25 & 25 & 25 & 21 & 21 & 21 & 44 & 44 & 44 & 31 & 31 & 31 \\
\hline Custos da produção agropecuária & 138 & 213 & 208 & 121 & 145 & 178 & 278 & 483 & 1359 & 164 & 242 & 1421 \\
\hline $\begin{array}{l}\text { Custos de compras para a } \\
\text { alimentação humana }\end{array}$ & 1535 & 1757 & 1576 & 1102 & 932 & 1107 & 1028 & 857 & 822 & 1248 & 1215 & 1215 \\
\hline Custo da alimentação humana & 1699 & 1948 & 2070 & 1323 & 1261 & 1494 & 1563 & 1497 & 1463 & 1572 & 1538 & 1538 \\
\hline $\begin{array}{l}\text { Margem líquida da família sem } \\
\text { festividades }\end{array}$ & -281 & 433 & 3618 & 2 & 906 & 3548 & 1327 & 4770 & 1000 & 964 & 2843 & 8745 \\
\hline $\begin{array}{l}\text { percentagem da produção vegetal } \\
\text { nas receitas }\end{array}$ & 42,4 & 63,5 & 84,0 & 37,9 & 59,1 & 78,3 & 67,3 & 78,7 & 89,3 & 48,7 & 69,0 & 81,6 \\
\hline $\begin{array}{l}\text { percentagem da produção animal } \\
\text { nas receitas }\end{array}$ & 57,6 & 36,5 & 16,0 & 62,1 & 40,9 & 21,7 & 32,7 & 21,3 & 10,7 & 51,3 & 31,0 & 18,4 \\
\hline $\begin{array}{l}\text { percentagem dos custos da } \\
\text { alimentação nas receitas }\end{array}$ & 109,2 & 75,1 & 35,1 & 91,5 & 54,5 & 28,6 & 49,3 & 22,2 & 8,2 & 58,2 & 33,3 & 13,1 \\
\hline $\begin{array}{l}\text { Renda diária per capita sem } \\
\text { festividade }\end{array}$ & 0,00 & 0,17 & 1,24 & 0,00 & 0,41 & 1,39 & 0,61 & 2,18 & 6,85 & 0,44 & 1,30 & 3,99 \\
\hline $\begin{array}{l}\text { Linha da pobreza sem custos com a } \\
\text { alimentação }\end{array}$ & & 0,58 & & & 0,54 & & & 0,65 & & & 0,79 & \\
\hline
\end{tabular}

Fonte: Modelos de PLE (Deus, 2018).

No que diz respeito à margem líquida sem incluir os custos com as festividades, de acordo com o esperado, quanto maior for a dimensão, maior será a margem líquida obtida. Na medida em que a margem líquida per capita, por si só, diz pouco sobre o bem-estar das famílias, essa margem foi comparada com a linha da pobreza, excluindo os custos com a alimentação anteriormente tratados. Assim, todas as explorações grandes $(7,5 \mathrm{ha})$ e as explorações médias ( $2,5 \mathrm{ha})$ de Bobonaro e Covalima apresentam, por distrito, níveis de rendimento per capita superiores à linha da pobreza, quando se retiram os custos da alimentação. Quer as explorações pequenas de todos os distritos, quer as explorações médias dos distritos de Ailéu e Ermera, estas apresentam rendimentos per capita inferiores à linha da pobreza excluindo os custos da alimentação. 
Em síntese, os resultados obtidos ao longo deste trabalho mostram que os distritos de Ailéu e Ermera são mais pobres que os distritos de Bobonaro e Covalima, e que destes dois últimos, Bobonaro é mais rico que Covalima. Estes resultados mostram a enorme massa de explorações de reduzidas dimensões incapazes de gerar rendimentos per capita superiores ou no mesmo nível da linha da pobreza. Para os agregados com rendimentos abaixo da linha da pobreza, é importante recordar que a percentagem e o número de agregados familiares com uma dimensão menor que um hectare são as seguintes: 67,4\% (3.539 agregados) em Ailéu; 64\% (9.226) em Ermera; 59,9\% (7.084) em Bobonaro, e 53,2\% (4.197) em Covalima. Já com área entre 1 e 5 hectares, é de 30,9\% (1.620) em Ailéu, e de 31,8\% (4.578) em Ermera.

\section{DISCUSSÃO DOS RESULTADOS}

É imenso o desafio que se coloca a Timor-Leste para fazer sair da linha da pobreza uma quantidade significativa de agregados familiares. Encontrar soluções de curto, médio e longo prazo para estes agregados familiares é o grande desafio para as políticas rurais e de desenvolvimento agrícola. Estas políticas têm sido desenvolvidas por um conjunto heterogêneo de entidades, coordenadas pelo governo do país, nas quais se salientam, na área rural e agrícola, o Ministério da Agricultura e Pescas e as suas dependências distritais e locais.

O plano de médio prazo para o desenvolvimento do setor agrícola (2014-2018) prevê cinco programas para cinco objetivos: 1) aumentar os níveis de segurança alimentar, reduzir a fome e a subnutrição; 2) aumentar a criação de valor dos produtos através da transformação e do marketing; 3) atingir nos recursos naturais níveis de produção e gestão sustentáveis; 4) contribuir para um maior equilíbrio da balança comercial através da substituição de importações, e 5) aumentar o rendimento e emprego nas zonas rurais. Os programas são: 1) aumento sustentável da produção e da produtividade; 2) melhoria do acesso ao mercado e criação de valor; 3) melhoria do suporte ambiental; 4) desenvolvimento organizacional do Ministério da Agricultura, e 5) conservação e gestão dos recursos naturais (Timor-Leste, 2014). No âmbito deste trabalho, estão os dois primeiros programas com impacto direto nos resultados econômicos dos agricultores, uma vez que os outros programas servem de suporte e regulação da atividade agrícola.

Desde sempre, a segurança alimentar tem sido uma das grandes preocupações em Timor-Leste dadas a natureza rural e a dependência da agricultura dos agregados familiares. Esta existe quando todas as pessoas, em todos os momentos, têm acesso físico, social e econômico a alimentos suficientes, seguros e nutritivos, para satisfazer suas necessidades e preferências alimentares por uma vida ativa e saudável (Food and Agriculture Organization, 1996). A segurança alimentar significa que os alimentos estão disponíveis, são e estão acessíveis e podem ser utilizados. Quando existe carência na geração de rendimento, pode acontecer carência alimentar, carência na satisfação de outras necessidades básicas, ou ausência de consumo de bens ditos ou considerados de luxo. A ocorrência, em simultâneo, das duas primeiras carências provoca situações de pobreza que, na maioria das vezes, têm reflexos intergeracionais.

Os modelos considerados assumem uma satisfação plena das necessidades alimentares em termos de energia e proteína por parte das famílias, pelo que os seus resultados contemplam segurança alimentar plena através da produção própria ou do mercado, expressando carência para a satisfação das outras necessidades básicas, dentre as quais se salientam o acesso à saúde e à educação, a habitação condigna, os bens de vestuário e de higiene e a participação nas atividades familiares e comunitárias de natureza festiva, entre outras necessidades.

Os resultados líquidos obtidos variam com a dimensão da exploração em termos de área, da composição do agregado familiar e do nível de atividades pecuárias observadas, em média, em cada distrito, sendo que todos os modelos assumem satisfação plena das necessidades alimentares. Se os modelos fossem simulados com carência alimentar, assumindo somente a satisfação de parte das necessidades alimentares, o que aconteceria seria um aumento do rendimento disponível para a satisfação das outras necessidades básicas. 
Mantendo tudo constante e variando somente a dimensão do agregado, alteram-se os resultados líquidos e também o posicionamento em relação à linha da pobreza. Se as explorações com valores abaixo da linha da pobreza - pequenas e médias de Ailéu e Ermera, e pequenas de Bobonaro e Covalima - suportarem agregados familiares de maior dimensão e tiverem os mesmos recursos, a sua posição relativamente à linha da pobreza agrava-se. Pelo contrário, se os seus agregados familiares tiverem uma menor dimensão, a sua distância em relação à linha da pobreza diminui.

Diversos estudos (TOMAK 2016a, 2016b, 2016c; Correia et al., 2018; United States Agency for International Development, 2012, 2013; Correia, 2014, 2015) mostram que é possível melhorar os rendimentos monetários por hectare para as culturas mencionadas, quer através das tecnologias, quer através de um melhor acesso aos mercados. O grande desafio é se estas alterações são suficientes para mover os agregados familiares, principalmente os de pequena dimensãomenor ou igual a um hectare, para níveis de rendimento que permitam um consumo superior ao da linha da pobreza.

\section{CONCLUSÕES}

A utilização da PLE para modelar agregados familiares com sistemas de agricultura como os observados mostrou-se adequada, embora possam e devam fazer-se melhorias na recolha, no armazenamento, na gestão e no tratamento de dados, tecnologicamente assistida e gerida, de modo a ter uma ferramenta de análise e monitorização dos sistemas de agricultura, com mapeamento geográfico.

Esta metodologia permite testar políticas, tecnologias, alterações reprodutivas e mudanças das normas sociais comunitárias, além de explorar os respectivos resultados e prever as consequências para o futuro dos agregados familiares e das comunidades rurais. Os resultados mostram que os agregados familiares com explorações agrícolas de pequena e, em alguns casos, também das de média dimensão, nas condições atuais, não geram rendimento suficiente para níveis de consumo e bem-estar acima da linha da pobreza. Alternativas de apoio ao rendimento, como o apoio direto ao rendimento, são possíveis, mas dependem dos recursos disponíveis para a sua implementação, enquanto, em médio e longo prazo, o aumento da área das explorações se afigura uma opção mais válida para quebrar o ciclo vicioso da pobreza.

O estudo demonstra de forma clara que os agregados familiares com áreas pequenas têm, na situação atual, dificuldades em romper com o ciclo vicioso da pobreza. Consequentemente, há necessidade de aumentar a dimensão das explorações familiares, como ficou patente através dos limites mínimos de área encontrados pelos modelos. Considera-se, assim, que deve haver uma política fundiária de apoio ao aumento da dimensão das explorações agrícolas. A experiência em outros contextos semelhantes aos de TimorLeste mostra, contudo, que as transformações fundiárias são bastante complexas e difíceis de se concretizarem, pelo que a política proposta, se considerada, deverá ser ajustada ao contexto sociocultural de cada comunidade.

A forma mais expedita de fazer sair os agregados familiares de situações abaixo da linha da pobreza é a do apoio direto ao rendimento dos agregados familiares. O governo de TimorLeste já o faz através da pensão anual de sobrevivência para os idosos e de subsistência mensal para os veteranos e/ou combatentes. Poderá ser equacionada a possibilidade de haver apoios diretos ao rendimento para os agregados familiares rurais mais necessitados.

\section{AGRADECIMENTOS}

Os autores agradecem à Fundação para a Ciência e a Tecnologia pelo suporte financeiro (UID/04007/2020).

\section{REFERÊNCIAS}

Asian Development Bank - ADB. (2015). Growing the non-oil economy a private sector assessment for Timor-Leste. Recuperado em15 de novembro de 2018, de 
https://www.adb.org/sites/default/files/institutional-document/161516/tim-growing-non-oileconomy.pdf

Belo, C. A. (2017). Coordenação da qualidade do café na cadeia agro-comercial: análise do caso das empresas que produzem e comercializam o café em Timor-Leste (Tese de Mestrado). Universidade de Évora, Évora.

Bernard, H. R. (1995). Research methods in anthropology: Qualitative and quantitative approaches. London, Altamira Press.

Correia, V. P., Costa, D., Profumo, G., \& Costa, A. M. (2018). Impact and opportunities of conservation agriculture on food and nutrition security in timor leste. Rome, Italy: UNTL-CNIC e FAO.

Correia, V. P. (2015). Integrating small-scale vegetable farmers to better access high end market in Dili: The case of Josephina Farms with contract farming, report. Díli, Timor-Leste: UNTL.

Correia, V. P. (2014). Analysis of linking farmers to markets for carrots, cabbages and snow peas in Aileu Vila, Maubisse and Hatubuilico, Timor Leste (Tese de doutorado). Curtin University, Australia.

Deus, C. C. (2018). Os sistemas de agricultura familiar de Timor-Leste: Uma Abordagem com Foco no Bemestar dos Produtores (Tese de doutorado). Universidade de Évora, Évora.

Direcção Nacional de Estatística - DNE. (2008). Timor-Leste Survey of Living Standards 2007. Díli, TimorLeste: DNE.

Direcção Nacional de Estatística - DNE. (2016). Poverty in Timor-Leste. Díli, Timor-Leste: DNE.

Food and Agriculture Organization - FAO. (1996). Declaration on world food security. World Food Summit. Rome, Italy: FAO.

Food and Agriculture Organization - FAO. (2012). The State of Food and Agriculture: Investing in agriculture for a better future. Rome, Italy: FAO.

Garner, E., Paula De La, A., \& Campos, O. (2014). Identifying the "family farm" an informal discussion of the concepts and definitions. Rome, Italy: FAO. Recuperado em15 de novembro de 2018, de www.fao.org/economic/esa

Hazell, P. B. R., \& Norton, R. D. (1986). Mathematical programming for economic analysis in agriculture (400 p.). New York: MacMillan Publishing Company.

Heady, H. F. (1958). Vegetational changes in the California annual type. Ecology, 39(3), 1.

Hildebrand, P., Breuer, N., Cabrera, V., \& Sullivan, A. (2003). Modeling diverse livelihood strategies in Rural livlihood systems using ethnographic linear programming (Staff Paper Series, SP03-5). Gainesville: University of Florida, Food and Resource Economics Department.

Rendes, J. (2013). Análise de influência da utilização dos fatores da produção no aumento da produção de arroz no subdistrito de Maliana, Distrito de Bobonaro em Timor-Leste (Tese de Mestrado). Universidade de Évora, Évora.

Rubzen, M. F., Correia, P. V., Sasinha, J. N., Janes, J. A., Ximenes, F. T., Araújo, C. M., \& Correia, J. (2010). Analysis of Farming Systems in East Timor. Díli, Timor-Leste: UNTL.

Timor-Leste. Ministry of Agrigulture and Fisheries. Agriculture sector development. (2014). Medium term operation plan (2014-2018). Díli, Timor-Leste: RDTL.

TOMAK. (2016a). A Market Analysis of Selected Agricultural Products, Technical Report 1. Díli, Timor-Leste: Adam Smith International, Mercy Crops e Australian Aid.

TOMAK. (2016b). Market System \& Value Chains Assessment, Technical Report 3. Díli, Timor-Leste: Adam Smith International, Mercy Crops e Australian Aid.

TOMAK. (2016c). Potential for Improving On-farm Productivity of Selected Agricultural and Livestock Enterprises, Technical Report 2. Díli, Timor-Leste: Adam Smith International, Mercy Crops e Australian Aid.

United States Agency for International Development - USAID. (2012). An Evaluation of the Development Communities through Intensive Agriculture (DOCIA)/Dezenvolve Agricultura Comunitária (DAC) Project. Díli, Timor-Leste: USAID.

United States Agency for International Development - USAID. (2013). Performance evaluation of the USAID/Timor-Leste consolidating cooperative and agribusiness recovery (COCAR) project, Final Report. Díli, Timor-Leste: USAID.

Wilsey, D., Gill, T., \& Rios, A. (2012, July 1-4). Participation begets integration: lessons learned from incorporating ethnography into linear programming. In Producing and reproducing farming systems. New modes of organisation for sustainable food systems of tomorrow. $10^{\text {th }}$ European IFSA Symposium, Aarhus, Denmark: International Farming Systems Association. 
World Bank (2018). Timor-Leste systematic country diagnostic. Pathways for a New Economy and Sustainable Livelihoods. Díli, Timor-Leste: World Bank. Recuperado em 10 de dezembro de 2018, de http://documents.worldbank.org/curated/en/524131528837983427/pdf/TL-SCD-0228B-lowres03212018.pdf

Ye, J., \& Pan, L. (2016). Concepts and realities of family farming in Asia and the Pacific (No. 139) Brasília, DF: IPC-IG.

Submetido em: 18/out/2019

Aceito em: 19/maio/2020

Classificação JEL: Q01, Q12, Q15 E Q18 